\title{
Simultaneous Measurements of Corrosion Potential and Hydrogen Permeation Current in Atmospheric Corrosion of Steel
}

\author{
Saya AJITO, ${ }^{1) *}$ Eiji TADA, ${ }^{2)}$ Azusa $\mathrm{OO}^{2)}$ and Atsushi NISHIKATA ${ }^{21}$ \\ 1) Department of Materials Science and Engineering, School of Materials and Chemical Technology, Tokyo Institute of Tech- \\ nology. Now at Institute for Materials Research, Tohoku University, 2-1-2 Katahira, Aobaku, Sendai, Miyagi, 980-8577 Japan. \\ 2) Department of Materials Science and Engineering, School of Materials and Chemical Technology, Tokyo Institute of \\ Technology, 2-12-1 Ookayama, Meguro-ku, Tokyo, 152-8552 Japan.
}

(Received on February 22, 2019; accepted on April 10, 2019; J-STAGE Advance published date: June 29, 2019)

\begin{abstract}
To investigate hydrogen absorption behavior into carbon steel during corrosion in an aqueous sodium chloride $(\mathrm{NaCl})$ droplet, a simultaneous measurement system of the corrosion potential, $E_{\text {corr }}$ and hydrogen permeation current, $i_{\text {per }}$ was developed using the Kelvin probe (KP) technique and the DevanathanStachurski (DS) method, respectively. This system outputs the interrelation between corrosion and hydrogen absorption into steel throughout the drying process of an $\mathrm{NaCl}$ droplet. Our results showed that hydrogen absorption into the steel occurred when the $E_{\text {corr }}$ shifted in less noble direction under wet conditions, and ceased at a higher potential of $E_{\text {corr }}$ when the steel surface dried up. Based on the results of the transients of the $i_{\text {per, }}$ the amount of hydrogen absorbed during the drying of the $\mathrm{NaCl}$ droplet increased with $\mathrm{NaCl}$ concentration, which was attributed to the negative shift of the $E_{\text {corr }}$. Furthermore, the amount of hydrogen absorbed within one wet-dry cycle changed with the number of cycles, due to the expansion of the corroded area and the formation of iron rust.
\end{abstract}

KEY WORDS: Devanathan-Stachurski method; Kelvin probe; thin electrolyte layer; iron rust; wet-dry cycle; hydrogen absorption.

\section{Introduction}

In recent years, hydrogen embrittlement (HE) of steels has been a great concern because the HE susceptibility of the steels is highly relevant with the strength of the steels. ${ }^{1,2}$ Since most of the steels are used in ambient atmospheres, the $\mathrm{HE}$ is induced by the hydrogen atoms generated in atmospheric corrosion. Thus, it is necessary to clarify the hydrogen absorption mechanism of corroding steel in atmospheric environments.

When steels are exposed to atmospheric conditions, hydrogen atoms can be generated by a cathodic reduction reaction of water or protons in the water film. Some of the hydrogen atoms generated are absorbed and diffuse into the interior bulk of the steel. Some researchers have suggested that the diffusive hydrogen atoms are associated with $\mathrm{HE}$ degradation of the steel, ${ }^{3,4)}$ in which the diffusive hydrogen interacts with metallographic defects, such as dislocations and vacancies, in the material. ${ }^{5,6)}$ In addition, HE susceptibility also depends on the amount of diffusive hydrogen atoms in the steel. ${ }^{6,7)}$ The critical amount of diffusive hydrogen atoms for HE degradation has been investigated in several studies. ${ }^{8-11)}$ For high tensile-strength steels of 1,200$\mathrm{MPa}$ grade, the critical amount of diffusive hydrogen atoms

* Corresponding author: E-mail: ajito@imr.tohoku.ac.jp DOI: https://doi.org/10.2355/isijinternational.ISIJINT-2019-113 is roughly estimated to be less than several ppm hydrogen. ${ }^{12)}$ Therefore, it is important to measure the degree of diffusive hydrogen atom absorption in steel as well as the absorption mechanism.

Various techniques have been used to detect and evaluate diffusive hydrogen atom in materials, such as thermal desorption analysis and spectroscopy ${ }^{13,14)}$ and electrochemical permeation using the Devanathan-Stachurski (DS) method. ${ }^{15-18)}$ The thermal desorption approach can be used to measure the amount of absorbed hydrogen in steel while differentiating among trapping sites. ${ }^{19)}$ This ex-situ technique is quite effective; however, it cannot be applied to in-situ monitoring of the absorbed hydrogen during steel corrosion. On the other hand, the DS method, an electrochemical permeation technique, is an in-situ technique to detect the diffusive hydrogen atoms by analyzing the electrochemical oxidation current. Therefore, it can be said that the DS method has a big advantage on in-situ monitoring of the diffusive hydrogen atoms in corroding steel over other techniques.

It is well-known that atmospheric corrosion proceeds in a thin electrolyte layer, which forms in ambient conditions with rain or dew condensation. ${ }^{20)}$ Corrosion potential measurements are key to determining the atmospheric corrosion activity of steel and can be performed easily in bulk solutions, simply by inserting reference electrodes into the solution. Although it is difficult to measure the corrosion 
potential of steel in a thin electrolyte layer with the reference electrodes, the information about corrosion potential is required to investigate hydrogen absorption into corroding steel in atmospheric environments. So far, several researchers have discussed the relationship between the corrosion potential of steel and hydrogen absorption behavior in atmospheric environments. ${ }^{21,22)}$ Tsuru et al. measured the corrosion potential of steel under wet-dry cyclic conditions using a Luggin capillary connected to a silver/silver chloride $(\mathrm{Ag} / \mathrm{AgCl})$ reference electrode through a salt bridge, together with the hydrogen permeation current. ${ }^{21)}$ However, the application of this system is limited. Specifically, the Luggin capillary is set in the thin electrolyte layer; however, the electrolyte layer thickness and solution chemistry change due to leakage of chloride ions from the salt bridge.

Furthermore, it is hard to investigate corrosion behavior soon before the drying out of the electrolyte. The Kelvin probe (KP) technique, which can measure Volta potential difference between a metallic material and a Kelvin probe, should be one of the solutions for the monitoring of corrosion potential of metallic materials in a thin electrolyte layer. $^{23-25)}$ By combining the KP technique with the DS method, the relationship between steel corrosion and hydrogen absorption into steel in atmospheric environments can be investigated without artifacts caused by inserting reference electrodes into the environments.

In this study, we introduce a newly developed simultaneous measurement system of the corrosion potential and hydrogen permeation current to investigate the hydrogen absorption mechanism of steel undergoing atmospheric corrosion. The hydrogen absorption behavior of corroding steel under wet-dry cyclic corrosion conditions is also discussed based on our results.

\section{Experimental}

\subsection{Sample}

The material used in this study was a $0.7-\mathrm{mm}$-thick coldrolled steel sheet. Table 1 shows the chemical composition of the material. The steel sheet was cut into a small coupon of $25 \times 25 \mathrm{~mm}^{2}$. Both sides of the coupon were ground with waterproof silicon carbide ( $\mathrm{SiC}$ ) abrasive papers to the Japan Industrial Standard (JIS) of 1000 grit. Chemical etching was carried out in a 10 mass $\%$ hydrochloric acid $(\mathrm{HCl})$, followed by placing the sample in a commercial chemicaletching solution (CPL-100; Ryoko Co., Ltd., Japan) at 308 $\mathrm{K}$ for $3 \mathrm{~min}$. After chemical etching, the coupon was again immersed in a 10 mass $\% \mathrm{HCl}$ solution and, subsequently, in a saturated $\mathrm{NaHCO}_{3}$ solution for neutralization.

Figure 1 shows a schematic diagram of the sample used for the measurements of hydrogen permeation current, hereafter $i_{\text {per }}$, during the drying of an $\mathrm{NaCl}$ droplet. The surface area exposed to the $\mathrm{NaCl}$ droplet $\left(0.2 \mathrm{~cm}^{2}\right)$, which was used for the hydrogen-entry side, was prepared by sealing the surface with a tape, as shown in Fig. 1(a). On

Table 1. Chemical composition of steel (mass\%).

\begin{tabular}{cccccc}
\hline $\mathrm{C}$ & $\mathrm{Si}$ & $\mathrm{Mn}$ & $\mathrm{P}$ & $\mathrm{S}$ & $\mathrm{Fe}$ \\
\hline 0.020 & 0.01 & 0.18 & 0.015 & 0.007 & Bal. \\
\hline
\end{tabular}

the other hand, the exposed surface with the same area for the hydrogen-withdrawal side was electrodeposited by Pd, as shown in Fig. 1(b). The electrodeposition was conducted in a Pd-plating solution (K-pure Pd; Kojima Chemical Co. Ltd., Japan) at a constant current density of $-15 \mathrm{~mA} / \mathrm{cm}^{2}$ for $58 \mathrm{~s}$ at $308 \mathrm{~K}$, to achieve a Pd thickness of $400 \mathrm{~nm}$. After the above procedure, the coupon was cleaned with ethanol $(\mathrm{EtOH})$ and ultrapure water $(18 \mathrm{M} \Omega \cdot \mathrm{cm}$ at $298 \mathrm{~K})$, and then used as a sample in the following experiments.

\subsection{Simultaneous Measurements of Corrosion Poten- tial and Hydrogen Permeation Current}

Figure 2 shows a schematic diagram of the simultaneous measurement system for the corrosion potential and hydrogen permeation current, hereafter $E_{\text {corr, }}$ and $i_{\text {per. }}$ The steel coupon sample prepared by the procedure described in Section 2.1 was pinched with the upper and lower parts of the DS cell. As shown in Fig. 2, the steel surface without a Pd coating faced upwards for air exposure. The steel surface with a Pd coating faced towards the electrolyte solution in (a) Hydrogen-entry side

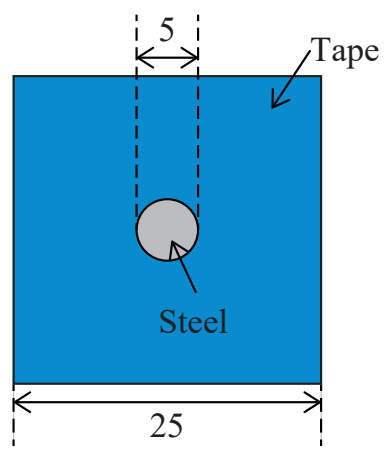

(b)Hydrogen-withdrawal side

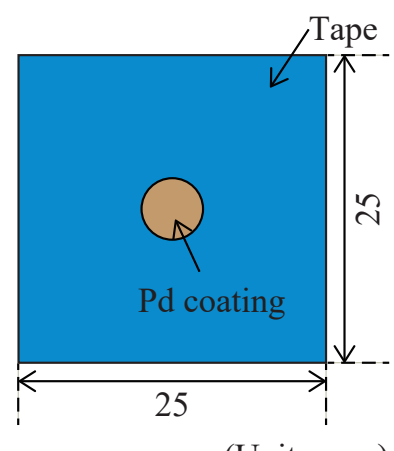

(Unit : mm)
Fig. 1. Schematic diagram of the sample: (a) hydrogen-entry side and (b) hydrogen-withdrawal side. (Online version in color.)

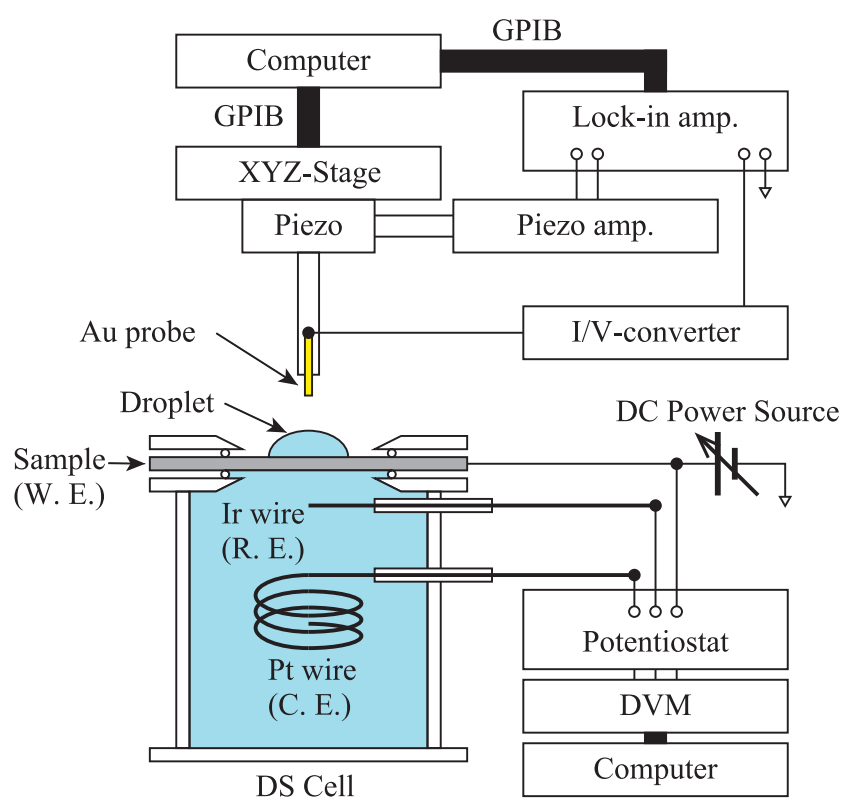

Fig. 2. Schematic diagram of the experimental setup. (Online version in color.) 
the DS cell. In the DS cell, a Pt wire (diameter: $0.4 \mathrm{~mm}$ ) and an Ir wire (diameter: $0.5 \mathrm{~mm}$ ) were introduced as the counter electrode and reference electrode, respectively, for electrochemical polarization measurements. The electrolyte solution in the DS cell was a $0.2-\mathrm{mol} / \mathrm{dm}^{3} \mathrm{NaOH}$ solution. The exposed surface was polarized at a constant potential of $+0.1 \mathrm{~V}$ with respect to the reference Ir wire electrode for polarization current measurements. After the polarization current reached values lower than $100 \mathrm{nA} / \mathrm{cm}^{2}$, the following corrosion tests commenced.

A $30-\mu \mathrm{L}$ droplet of $\mathrm{NaCl}$ solution with different concentrations was placed on the sample surface. The $\mathrm{NaCl}$ solution concentrations used in this study were 0.01 and $0.1 \mathrm{~mol} / \mathrm{dm}^{3}$. The chloride deposition density on the sample corresponded to 0.89 and $8.9 \mathrm{~g} / \mathrm{m}^{2}$ for the 0.01 and $0.1 \mathrm{~mol} /$ $\mathrm{dm}^{3} \mathrm{NaCl}$ solution concentrations, respectively. The $\mathrm{NaCl}$ droplet was left on the sample to dry at $298 \mathrm{~K}$ and a relative humidity (RH) of 20 to $30 \%$. The relative humidity in the environment was much lower than a critical relative humidity of $\mathrm{NaCl}$ at $298 \mathrm{~K}$ and then the droplet completely dried out within around $1.5 \mathrm{~h}$. After the initial droplet had dried up completely, the same amount of ultrapure water $(30 \mu \mathrm{L})$ was put on the sample surface and left to dry under the same conditions. The application of ultrapure water was repeated several times after the second wet-dry cycle.

In this study, the KP technique was applied to measure the Volta potential difference, hereafter $E_{\mathrm{V}}$, between the sample and the KP. A 1-mm-diameter gold ( $\mathrm{Au}$ ) KP wire (99.5\%; Nilaco Corporation, Japan) was positioned above the exposed surface. The KP was vibrated along with a bimorph-type piezoactuator (LPD3713X; Nihon Ceratec Co., Ltd., Japan). In this study, a small alternating current (AC) voltage signal from a lock-in amplifier (5610B; NF Corporation, Japan) was amplified by a piezodriver (AS904-150B; NF Corporation, Japan). The amplified AC voltage signal was applied to the piezoactuator to vibrate the KP. The vibration frequency of the probe was chosen as a constant value in the range of 170 to $240 \mathrm{~Hz}$, and the vibration amplitude was controlled to $20 \mu \mathrm{m}$ based on the characteristics of the piezoactuator.

In this study, $E_{\mathrm{V}}$ between the sample and the KP was measured using a parasitic capacitance method, ${ }^{26,27)}$ an improved null method. The AC current flowing between the sample and the KP was measured with a low-current amplifier (T-IVA001H; Turtle Industry Co., Ltd., Japan). The amplitude of the AC current was calculated against the direct current (DC) bias voltage. The DC bias voltage was applied to the circuit using a data acquisition (DAQ) device (USB-6215; National Instruments Corporation, USA). A personal computer with a custom-designed program written in LabVIEW (National Instruments Corporation, USA) was used for motion control of a motorized $z$-stage (MM-60Z; Chuo Precision Industrial Co., Ltd., Japan), to operate the DAQ device and record the AC signal outputs from the lock-in amplifier.

The $E_{\mathrm{V}}$ measured in this study was converted to $E_{\text {corr }}$ using the calibration line, based on the same method described by Stratmann et al. ${ }^{23)}$ Figure 3 shows the relationship between the $E_{\mathrm{V}}$ and $E_{\text {corr }}$ of various metals, such as $\mathrm{Zn}$, $\mathrm{Fe}, \mathrm{Ni}$, and $\mathrm{Cu}$, measured under a 1-mm-thick droplet of a $1-\mathrm{mol} / \mathrm{dm}^{3} \mathrm{Na}_{2} \mathrm{SO}_{4}$ solution using the KP technique and the

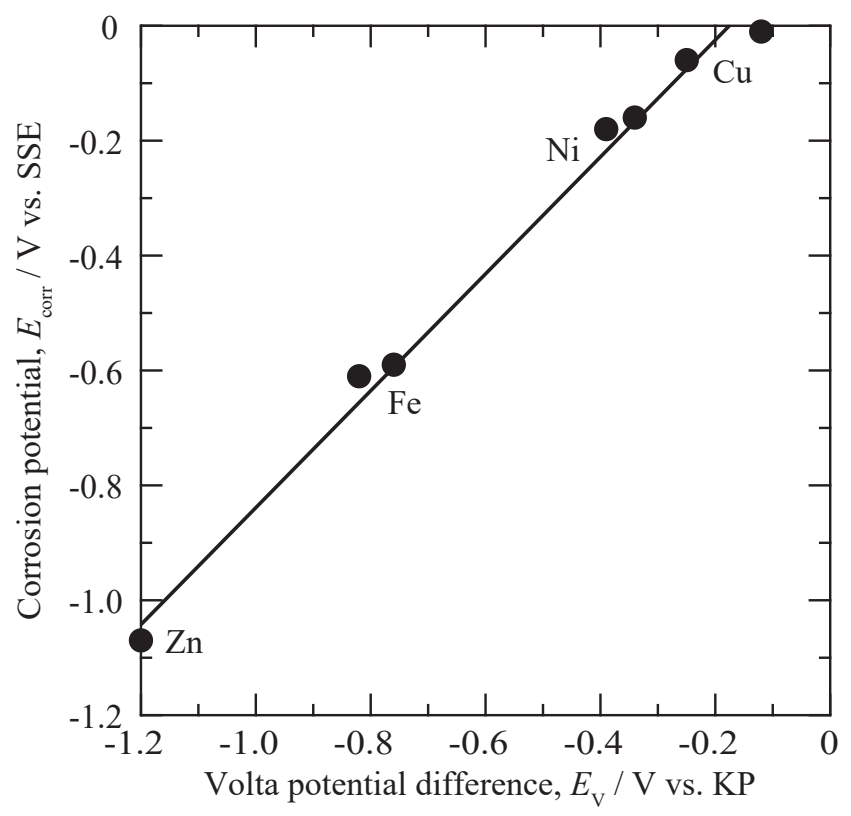

Fig. 3. Relationship between the corrosion potential, $E_{\text {corr }}$, and the Volta potential, $E_{\mathrm{v}}$, of various metals in a $1-\mathrm{mol} / \mathrm{dm}^{3}$ $\mathrm{Na}_{2} \mathrm{SO}_{4}$ solution.

conventional electrochemical method, with a Luggin capillary connected to a $\mathrm{Ag} / \mathrm{AgCl}$ reference electrode (SSE). As shown in Fig. 3, there was an almost perfect linear relationship between $E_{\mathrm{V}}$ and $E_{\text {corr }}$, as indicated by the slope value of 1.02 .

$$
E_{\text {corr }} / \mathrm{V} \text { vs. } \mathrm{SSE}=0.179+1.02 E_{\mathrm{V}} / \mathrm{V} \text { vs. KP }
$$

Using the KP method, $E_{\text {corr }}$ for a sample under the $\mathrm{NaCl}$ droplet can be estimated by measuring $E_{\mathrm{V}}$. All of the $E_{\mathrm{V}}$ values measured with this measurement system were converted to $E_{\text {corr }}$. The $E_{\text {corr }}$ values appearing in this paper are in reference to the SSE.

\section{Results}

\subsection{Simultaneous Measurements of the Corrosion Potential and Hydrogen Permeation Current throughout the Drying of an $\mathrm{NaCl}$ Droplet}

Figure 4 shows transients of $E_{\text {corr }}$ of steel and $i_{\text {per }}$ during the drying of a $30-\mu \mathrm{L}$ droplet of a $0.1-\mathrm{mol} / \mathrm{dm}^{3} \mathrm{NaCl}$ solution; the arrows on the $E_{\text {corr }}$ transient denote the timing of droplet application to the surface. As shown in the figure, simultaneous measurements of $E_{\text {corr }}$ and $i_{\text {per }}$ were performed successfully throughout the drying of the $\mathrm{NaCl}$ droplet by combining the KP technique and the DS method. This indicates that the hydrogen absorption behavior can be investigated in detail throughout the wet-dry corrosion process, and that hydrogen absorption behavior into the steel is associated with corrosion reaction on steel. Furthermore, using the KP technique, the information about steel corrosion in the droplet is obtained in-situ, without any artifacts caused by introducing reference electrodes.

\subsection{Changes in the Corrosion Potential and Hydrogen Permeation Current during the Drying of an $\mathrm{NaCl}$ Droplet}

Similar transients of $E_{\text {corr }}$ and $i_{\text {per }}$ were obtained during 
(a)

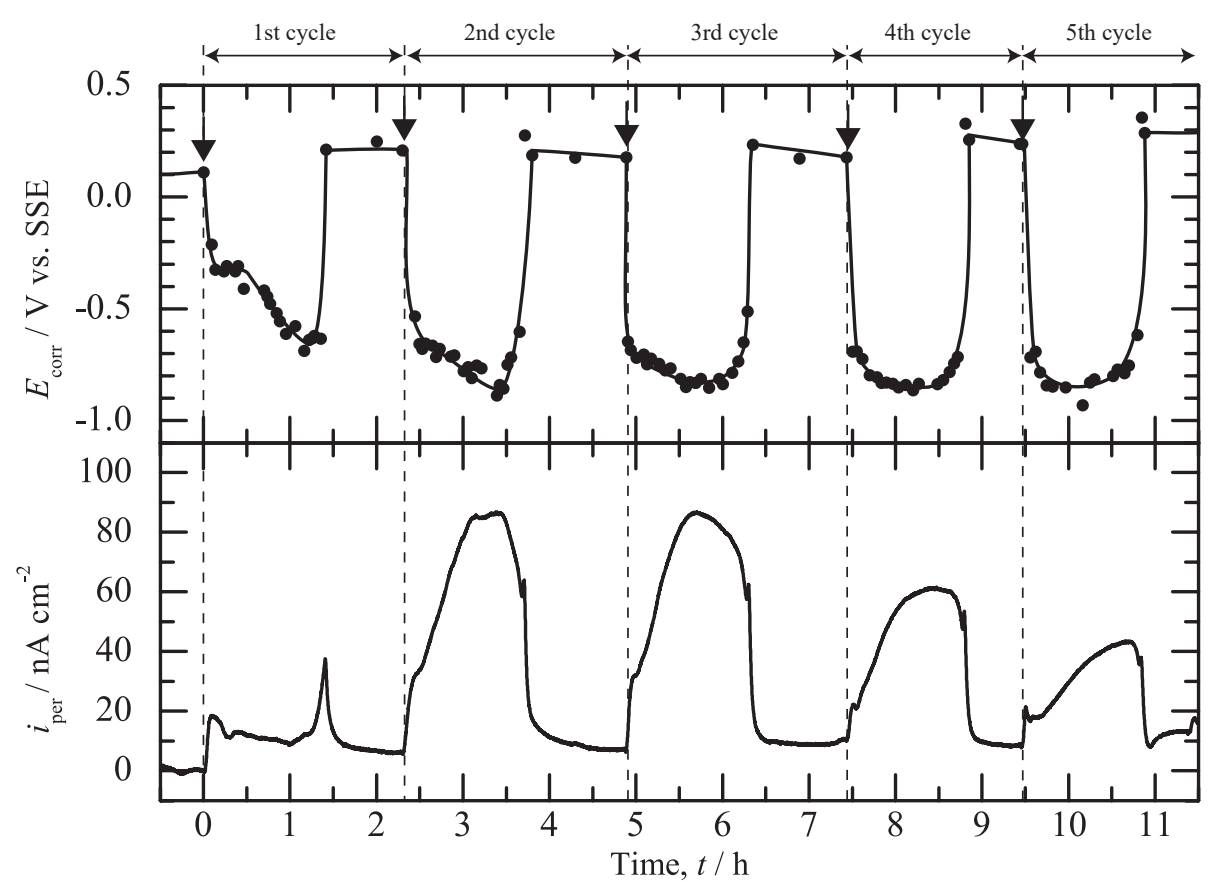

Fig. 4. Changes in (a) $E_{\text {corr }}$ and (b) $i_{\text {per }}$, during the drying of a $0.1-\mathrm{mol} / \mathrm{dm}^{3} \mathrm{NaCl}$ droplet. The arrows on the $E_{\text {corr }}$ transient denotes the timing of droplet application to the surface.
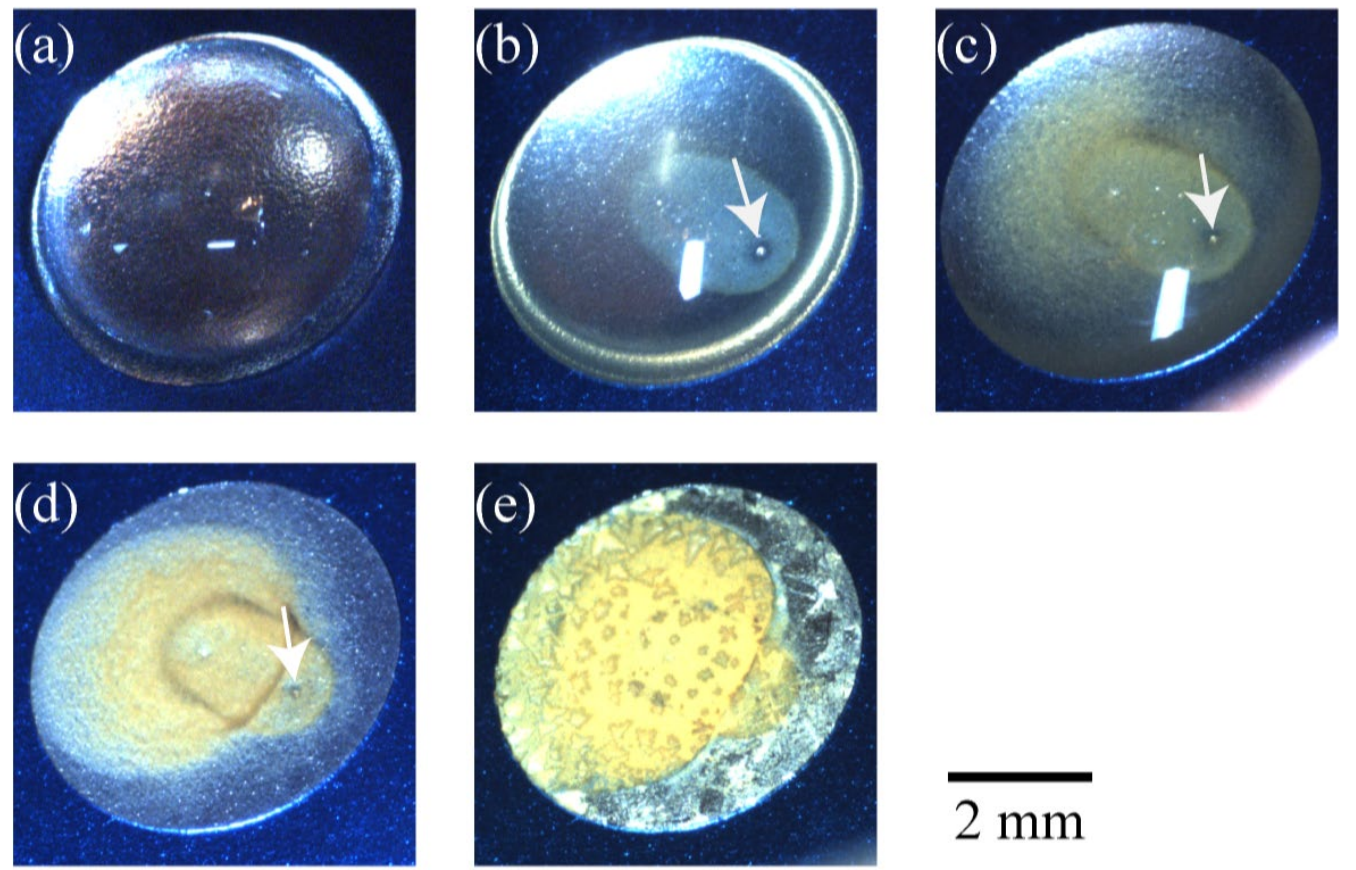

\section{$2 \mathrm{~mm}$}

Fig. 5. Change in the corrosion morphology of the steel surface during the 1st wet-dry cycle: (a) 10, (b) 30, (c) 50, (d) 70, and (e) 90 min. (Online version in color.)

the drying of the $\mathrm{NaCl}$ droplet, with the exception of the 1 st drying period (Fig. 4). During the 1st drying period, $E_{\text {corr }}$ exhibited two shoulders. Additionally, the evolution of $i_{\text {per }}$ after $\mathrm{NaCl}$ droplet application was smaller than after the 2 nd drying period. In the 1 st drying period, $E_{\text {corr }}$ shifted to the negative direction just after the $\mathrm{NaCl}$ droplet was placed, i.e., to $-0.3 \mathrm{~V}$; simultaneously, $i_{\text {per }}$ displayed a small peak. This indicates that corrosion reaction on steel commenced under the droplet and that the hydrogen absorption into steel was also initiated. During the successive drying of the droplet, $E_{\text {corr }}$ shifted gradually to a more negative direction, which was attributed to the further enhancement of the anodic dissolution reaction of iron. However, $i_{\text {per }}$ did not change significantly with the negative shift of $E_{\text {corr }}$ during the 1 st cycle. Before the droplet dried up completely, $i_{\text {per }}$ showed a relatively large spike.

To investigate the behavior of $E_{\text {corr }}$ and $i_{\text {per }}$ during the $1 \mathrm{st}$ drying period, surface morphology changes in the corroding steel were observed. A small pit, denoted by a white arrow (Fig. 5(b)), was observed on the steel surface within 30 min after the application of the $\mathrm{NaCl}$ droplet, and corrosion products of iron rust formed around the pit in Fig. 5(c). In the early stage of the 1 st drying period, the corrosion reaction in which a small pit acted as an anode was not sig- 
nificantly active, based on $E_{\text {corr }}$ and surface observation. As shown in Fig. 5(d), the amount of the iron rust precipitated on the steel surface increased before the droplet had dried up completely, as $E_{\text {corr }}$ approached to the minimum value. This suggests that corrosion reaction was more activated in the later stage of the drying period while the droplet was being dried. After the droplet dried up (Fig. 5(e)), $E_{\text {corr }}$ shifted to a very high potential, and $i_{\text {per }}$ began to decay with time. During this stage, no hydrogen absorption was induced, as there was no corrosion on the steel surface.

After the 2nd wet-dry corrosion cycle, nearly the same
$E_{\text {corr }}$ and $i_{\text {per }}$ transients were observed during the drying of the droplet, although the peak value of $i_{\text {per }}$ gradually decreased as the number of cycles increased. The transients of $E_{\text {corr }}$ and $i_{\text {per }}$ after the 2nd wet-dry corrosion cycle were quite different with those of the 1 st cycle. As seen in the transients of $E_{\text {corr }}$ and $i_{\text {per }}$ during the 2 nd drying cycle, $E_{\text {corr }}$ shifted significantly to $-0.8 \mathrm{~V}$ in the less noble direction (no shoulder near $-0.3 \mathrm{~V}$ ), and a relatively larger $i_{\text {per }}$ than that observed during the 1st drying cycle flowed during the drying process, just after application of the droplet to the sample surface. As $E_{\text {corr }}$ gradually decreased to $-0.8 \mathrm{~V}$ dur-
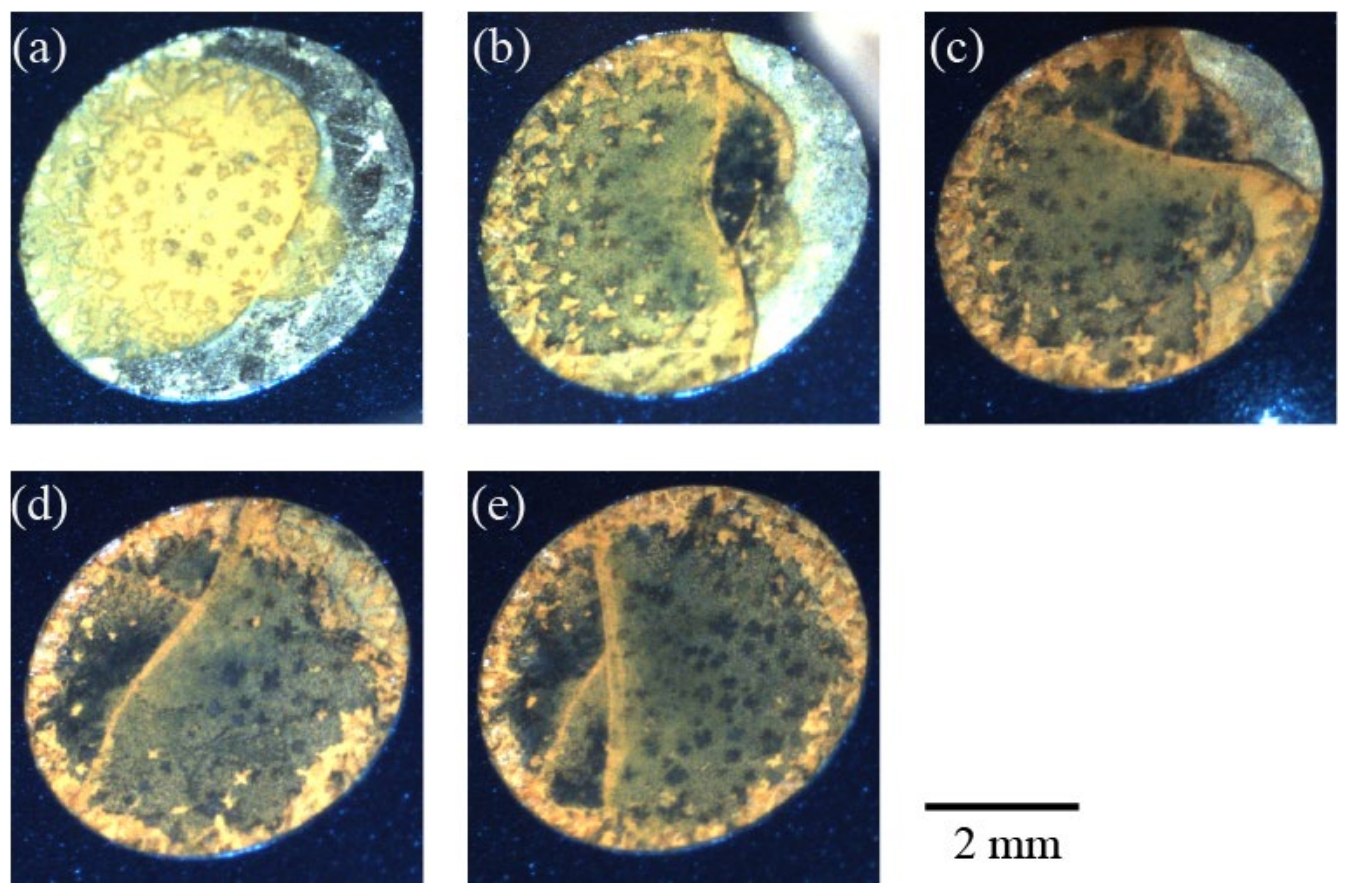

\section{$2 \mathrm{~mm}$}

Fig. 6. Surface morphology of steel after several wet-dry cycles under a droplet of $0.1-\mathrm{mol} / \mathrm{dm}^{3} \mathrm{NaCl}$ : (a) 1st, (b) 2nd, (c) 3 rd, (d) 4th and (e) 5th cycle. (Online version in color.)

(a)

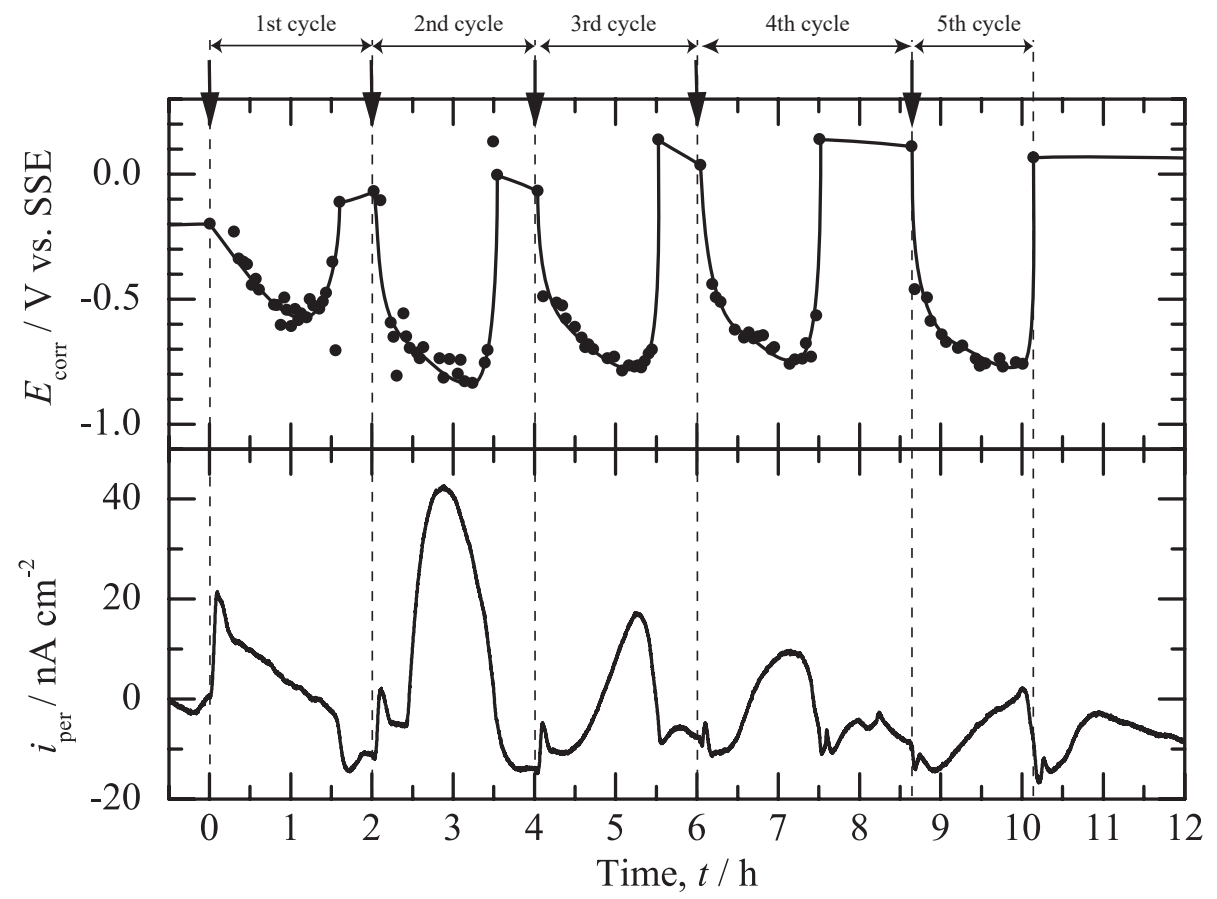

Fig. 7. Changes in (a) $E_{\text {corr }}$ and (b) $i_{\text {per }}$ during the drying of a $0.01-\mathrm{mol} / \mathrm{dm}^{3} \mathrm{NaCl}$ droplet. The arrows on the $E_{\text {corr }}$ transient denotes the timing of droplet application to the surface. 

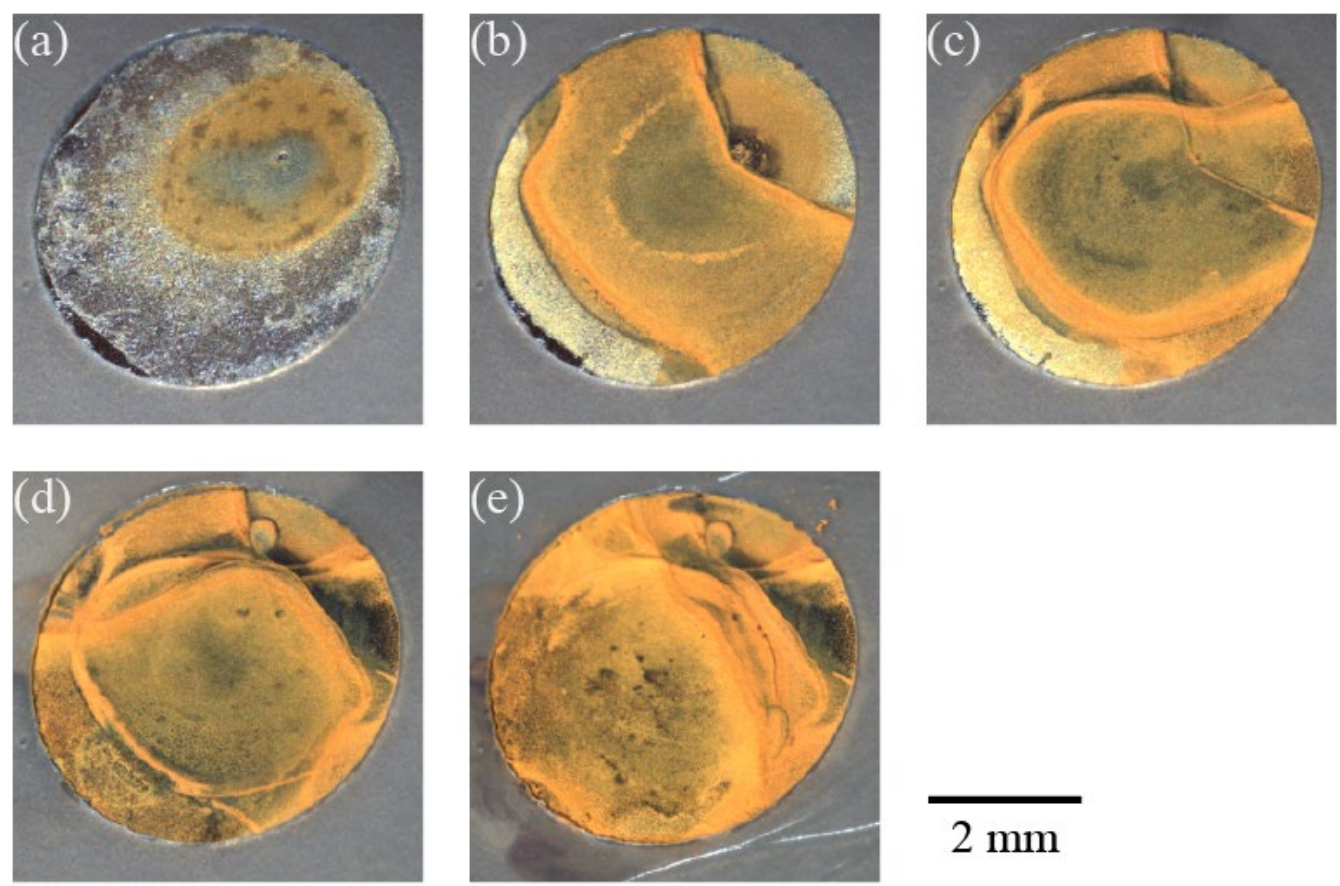

Fig. 8. Surface morphology of steel after several wet/dry cycles under a droplet of $0.01-\mathrm{mol} / \mathrm{dm}^{3} \mathrm{NaCl}$ : (a) $1 \mathrm{st}$ (b) $2 \mathrm{nd}$, (c) $3 \mathrm{rd}$, (d) 4th, and (e) 5th cycle. (Online version in color.)

ing the drying of the droplet, $i_{\text {per }}$ increased to its peak value. Before the droplet dried up completely, $E_{\text {corr }}$ increased significantly to a noble potential and then $i_{\text {per }}$ decreased to a residual current.

Figure 6 shows the changes in surface morphology of the corroding steel in the wet-dry cyclic corrosion test with a $0.1-\mathrm{mol} / \mathrm{dm}^{3} \mathrm{NaCl}$ droplet. In the early stage of the cycles, the steel surface was covered in part by iron rust; this rusted area expanded with the number of the wet-dry cycles, suggesting that anodic and cathodic sites were distributed heterogeneously over the corroding steel in the wet-dry cycles. As shown in the photographs taken after the 4th cycle, the surface was completely covered with iron rust. These results indicate that hydrogen absorption into the corroding steel occurs under the iron rust during the drying of the $\mathrm{NaCl}$ droplet and that the decrease in the peak value of $i_{\text {per }}$ observed after the 4th cycle in Fig. 4 is associated with the formation of iron rust over the entire steel surface.

Figure 7 shows the transients of $E_{\text {corr }}$ and $i_{\text {per }}$ of steel exposed to a $0.01-\mathrm{mol} / \mathrm{dm}^{3} \mathrm{NaCl}$ droplet (a lower concentration than that used in the case presented in Fig. 4); similar transients of $E_{\text {corr }}$ and $i_{\text {per }}$ were observed during the drying of the $\mathrm{NaCl}$ droplet at a lower initial concentration of $\mathrm{NaCl}$. In the case of $0.01 \mathrm{~mol} / \mathrm{dm}^{3}$, the peak values of $i_{\text {per }}$ decreased gradually after the 2 nd cycle as the number of wet-dry cycles increased, although the minimum $E_{\text {corr }}$ changed only slightly in the noble direction with the number of wet-dry cycles. The peak values of $i_{\text {per }}$ for $0.01 \mathrm{~mol} / \mathrm{dm}^{3}$ were lower compared with those for $0.1 \mathrm{~mol} / \mathrm{dm}^{3}$. Figure 8 shows the changes in surface morphology of the corroding steel for a $0.01-\mathrm{mol} / \mathrm{dm}^{3} \mathrm{NaCl}$ droplet; after the $3 \mathrm{rd}$ cycle, almost the entire surface was covered with iron rust, and the precipitation morphology of the iron rust did not change significantly over time. These results are similar to those presented under $0.1-\mathrm{mol} / \mathrm{dm}^{3} \mathrm{NaCl}$ exposure.

\section{Discussion}

4.1. Hydrogen Absorption Behavior of Corroding Steel As shown in Fig. 4, hydrogen absorption into the steel occurred under an $\mathrm{NaCl}$ droplet with the negative shift of $E_{\text {corr }}$. This indicates that corrosion reaction of steel was activated by the application of the $\mathrm{NaCl}$ droplet and that accordingly the hydrogen absorption into steel was also induced during the drying of the droplet. In the 1 st wet-dry cycle, $i_{\text {per }}$ on the whole was smaller than that for the wet-dry cycles after the 2nd cycle. As shown in Fig. 5, most of the surface of the corroding steel except for the pit was considered to be a cathodic site where the oxygen reduction reaction (ORR) caused an increase in the $\mathrm{pH}$ due to the formation of $\mathrm{OH}^{-}$ions. It means that only the pit was considered to be an anode where the hydrogen evolution reaction (HER) was accelerated due to the relatively lower $\mathrm{pH}$ compared with the cathodic regions. In this case, although $E_{\text {corr }}$ shifts gradually to a more negative direction during the drying of the droplet due to the enhancement of the anodic dissolution reaction of iron, the increase in $\mathrm{pH}$ almost on the whole surface and relatively higher $E_{\text {corr }}$ values are attributable to the low $i_{\text {per }}$ during the 1 st drying period.

Here we will consider the relationship between steel corrosion and hydrogen absorption into the steel based on the results of $E_{\text {corr }}$ and $i_{\text {per }}$ transients during the drying of $\mathrm{NaCl}$ droplets. Figure 9 shows the changes in the most negative corrosion potential during the drying, $E_{\text {corr, MIN }}$ and the amount of absorbed hydrogen per one wet-dry cycle, $N_{\mathrm{H}}$, with the number of wet-dry cycles in 0.1 and $0.01-\mathrm{mol} / \mathrm{dm}^{3}$ $\mathrm{NaCl}$ droplets. The values of $N_{\mathrm{H}}$ were calculated by integrating $i_{\text {per }}$ per one wet-dry cycle over time. The results showed that $N_{\mathrm{H}}$ increased with a negative shift of $E_{\text {corr, MIN }}$ up to the 2nd cycle; after the 3 rd cycle, $N_{\mathrm{H}}$ decreased, with a slight positive shift of $E_{\text {corr, MIN }}$. Furthermore, $N_{\mathrm{H}}$ for $0.1 \mathrm{~mol} / \mathrm{dm}^{3}$ was higher than that for $0.01 \mathrm{~mol} / \mathrm{dm}^{3}$ over the wet-dry test, 
which is related to a more negative $E_{\text {corr }}$ for $0.1 \mathrm{~mol} / \mathrm{dm}^{3}$. The more negative $E_{\text {corr }}$ for $0.1 \mathrm{~mol} / \mathrm{dm}^{3}$ was considered to be due to the enhancement of anodic dissolution reaction of iron at the higher concentration of $\mathrm{NaCl}$ droplets. These results shown in Fig. 9 means that higher concentration of $\mathrm{NaCl}$ enhances the hydrogen absorption with the relation to the negative shift of $E_{\text {corr }}$.

In order to investigate further the relationship between steel corrosion and hydrogen absorption behavior, $i_{\text {per }}$ and the corresponding $E_{\text {corr }}$ measured during the drying of the $\mathrm{NaCl}$ droplet during the wet-dry cyclic corrosion test were plotted in Fig. 10. As shown in Fig. 10, larger $i_{\text {per }}$ is frequently observed at less noble potentials. In Fig. 10, a straight line with the slope of $-240 \mathrm{mV} / \mathrm{dec}$ was drawn. The slope of $-240 \mathrm{mV} / \mathrm{dec}$ corresponds to the potential dependency of $i_{\text {per, }}$, which can be derived by assuming that Volmer reaction is the rate-determining step for the hydrogen evolution reaction (HER) on the steel surface. ${ }^{28,29}$ Although the plots of $i_{\text {per }}$ are scattered, the potential dependency of $i_{\text {per }}$ measured in this study is roughly along the line. This result indicates that the hydrogen absorption into steel during the

(a)

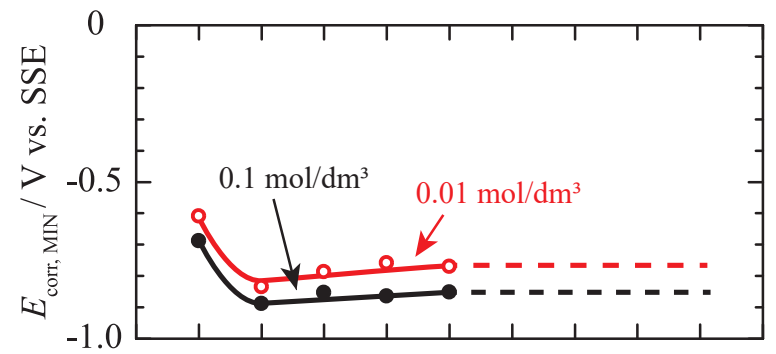

(b)

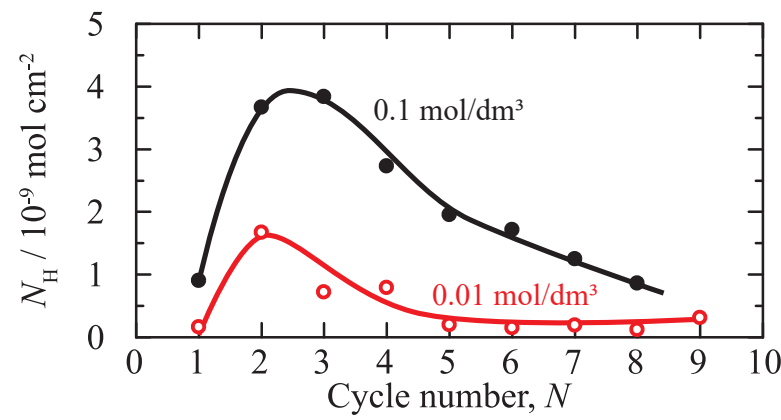

Fig. 9. Changes in (a) the most negative corrosion potential, $E_{\text {corr, MIN }}$, and (b) the amount of absorbed hydrogen into steel, $N_{\mathrm{H}}$, during each wet-dry cycle. (Online version in color.) drying of an $\mathrm{NaCl}$ droplet is enhanced basically with a negative shift of $E_{\text {corr }}$.

In addition, as shown in Fig. 10 , at the same $E_{\text {corr }}$, the greater the $\mathrm{NaCl}$ concentration, the more enhanced the hydrogen absorption. These results also indicate that hydrogen absorption enhancement is also associated with the acceleration of anodic dissolution on corroding steel during the drying of an $\mathrm{NaCl}$ droplet. The acceleration of the anodic dissolution of iron can produce large amounts of ferrous ions $\left(\mathrm{Fe}^{2+}\right)$ at anodic sites (Eq. (2)). The ferrous ions can be oxidized swiftly to ferric ions $\left(\mathrm{Fe}^{3+}\right)$ in the atmosphere containing oxygen. The ferric ions produce protons by the hydrolysis reaction of Eq. (3). ${ }^{30-32)}$ As a result, the

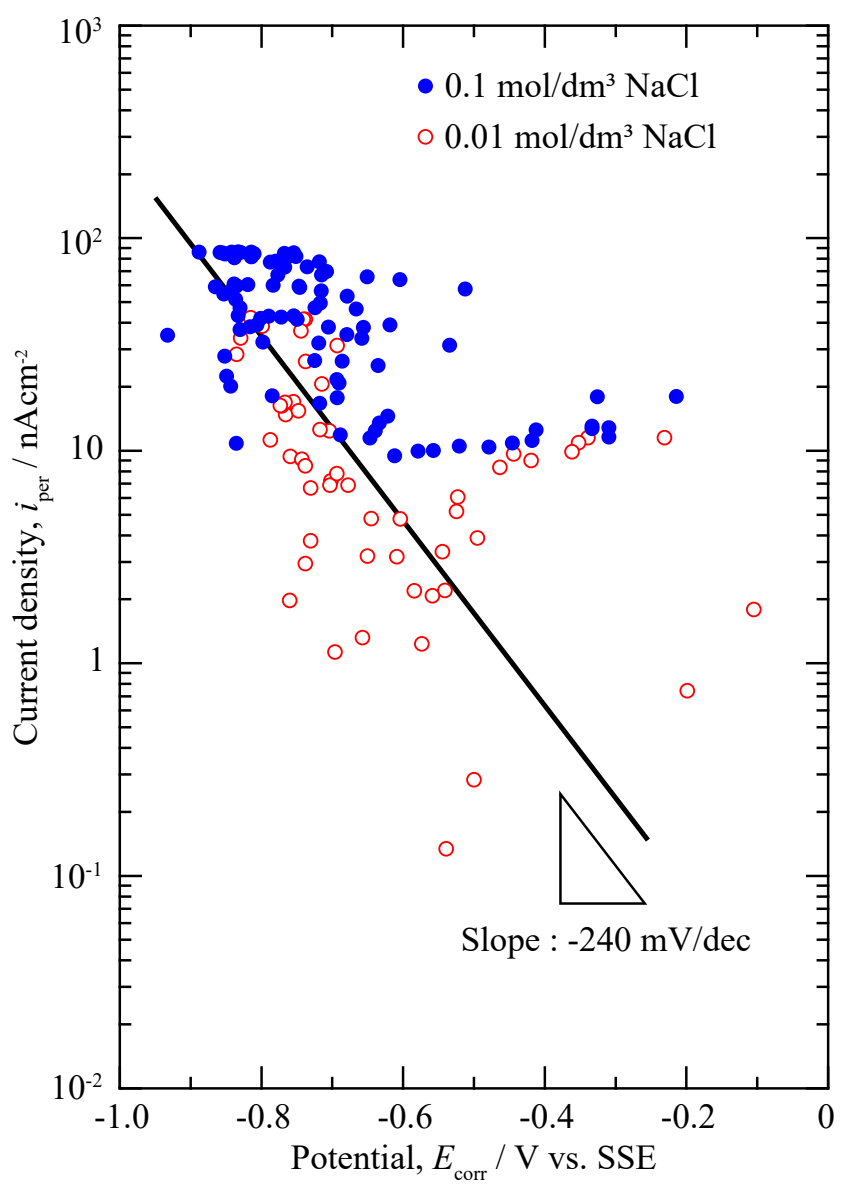

Fig. 10. Relationship between $i_{\text {per }}$ and $E_{\text {corr }}$ during the drying of an $\mathrm{NaCl}$ droplet. (Online version in color.)

(a) Early stage

(b) Later stage

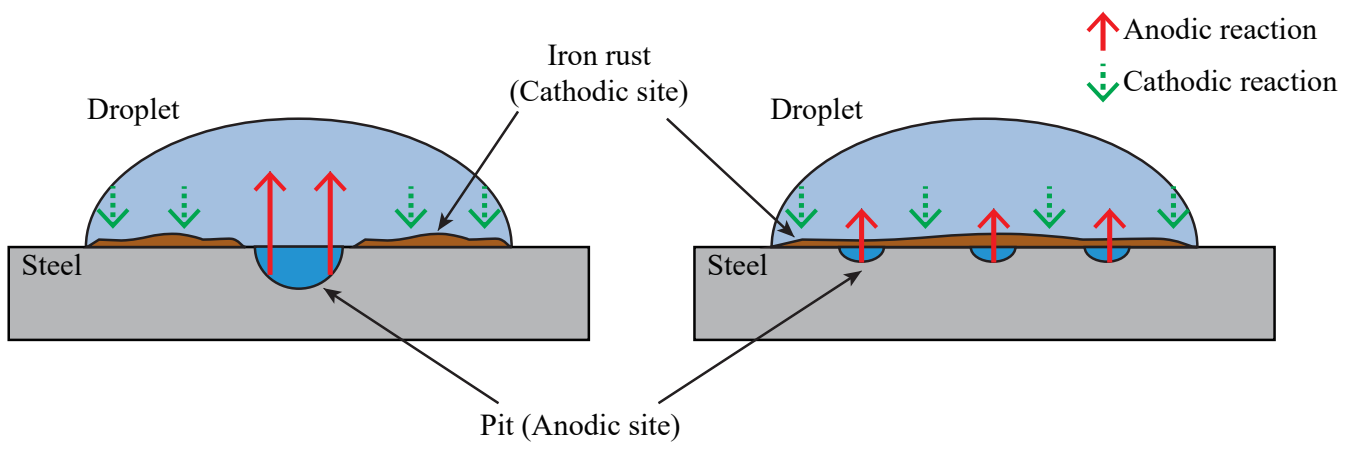

Fig. 11. Schematic diagram of steel corrosion in an $\mathrm{NaCl}$ droplet under wet-dry corrosion cycles: (a) Early stage and (b) Later stage. (Online version in color.) 
$\mathrm{pH}$ of the anode sites on the steel decreases compared with $\mathrm{pH}$ at the cathodic sites. Therefore, as the anodic dissolution of iron increases with the $\mathrm{NaCl}$ concentration, the $\mathrm{pH}$ at the anodic sites becomes lower and the hydrogen absorption is enhanced.

$$
\begin{array}{r}
\mathrm{Fe} \rightarrow \mathrm{Fe}^{2+}+2 \mathrm{e}^{-} \ldots \ldots \ldots \ldots \\
\mathrm{Fe}^{3+}+3 \mathrm{H}_{2} \mathrm{O} \rightarrow \mathrm{Fe}(\mathrm{OH})_{3}+3 \mathrm{H}^{+}
\end{array}
$$

\subsection{Hydrogen Absorption Mechanism into Steel under an $\mathrm{NaCl}$ Droplet}

Figure 11 shows a schematic diagram of the hydrogen absorption mechanism on steel during the drying of an $\mathrm{NaCl}$ droplet. As shown in Fig. 11(a), in the early stages of steel corrosion, anodic dissolution of iron occurs at local anodic sites, in which lower $\mathrm{pH}$ regions form; the local anodic sites are separated from local cathodic sites on the steel. This separation of anodic and cathodic sites disappears after several wet-dry cycles, with the formation of iron rust over the entire surface, as shown in Fig. 11(b). Therefore, in the early stage of steel corrosion, activation of the anodic dissolution of iron and the decrease in $\mathrm{pH}$ enhance hydrogen absorption by the steel. On the other hand, after the entire surface is covered with iron rust, hydrogen absorption is impeded mainly due to the positive shift of $E_{\text {corr }}$ and the mitigation of $\mathrm{pH}$ reduction. In addition, if the electrochemical reaction of iron rust occurs, the suppression of the hydrogen absorption may be impeded further because $E_{\text {corr }}$ shifts to a more positive potential.

\section{Conclusions}

In this study, a simultaneous measurement system of $E_{\text {corr }}$ and $i_{\text {per }}$ were applied to investigate hydrogen absorption behavior of steel in simulated atmospheric corrosion environments by combining the KP technique and the DS method. The relation between steel corrosion and hydrogen absorption behavior into steel during the drying of an $\mathrm{NaCl}$ droplet with different concentrations was discussed. The following summarizes our findings.

(1) Simultaneous measurements of $E_{\text {corr }}$ and $i_{\text {per }}$ were successfully conducted throughout the drying process of an $\mathrm{NaCl}$ droplet. The hydrogen absorption behavior of steel undergoing atmospheric corrosion was investigated in detail with respect to changes in $E_{\text {corr }}$.

(2) Hydrogen absorption was initiated just after steel corrosion commenced and continued until just before the droplet had dried up completely. At the end of the drying process, the hydrogen absorption was enhanced significantly. This was attributed to the enhancement of acidity at the anodic sites on the steel surface.
(3) The amount of hydrogen absorbed into the steel during the drying of $\mathrm{NaCl}$ droplet decreases as the number of wet-dry corrosion cycles increased except for the case of the 1 st wet-dry cycle. The was because the $E_{\text {corr }}$ shifted in noble direction and the mitigation of $\mathrm{pH}$ reduction.

(4) The amount of hydrogen absorbed into steel was enhanced as the chloride concentration in the $\mathrm{NaCl}$ droplet increased. This was attributed to the enhancement of anodic dissolution with increasing in the $\mathrm{NaCl}$ concentration.

\section{Acknowledgement}

A part of this work was financially supported by Iketani Science and Technology Foundation, JAPAN.

\section{REFERENCES}

1) R. M. Kain: Mater. Perform., 29 (1990), 60.

2) J. B. Gnanamoorthy: Mater. Perform., 29 (1990), 63.

3) T. Shiraga: Zairyo-to-Kankyo, 60 (2011), 236 (in Japanese).

4) M. Nagumo: Zairyo-to-Kankyo, 56 (2007), 132 (in Japanese).

5) M. Nagumo: Zairyo-to-Kankyo, 56 (2007), 343 (in Japanese)

6) M. Nagumo: Zairyo-to-Kankyo, 56 (2007), 382 (in Japanese).

7) R. Nishimura: Zairyo-to-Kankyo, 60 (2011), 177 (in Japanese).

8) K. Takai: Zairyo-to-Kankyo, 60 (2011), 230 (in Japanese).

9) S. Li, E. Akiyama, T. Shinohara, K. Matsuoka and W. Oshikawa: ISIJ Int., 53 (2013), 1062.

10) T. Omura: Zairyo-to-Kankyo, 58 (2009), 130 (in Japanese).

11) E. Akiyama, K. Matsukado, M. Wang and K. Tsuzaki: Corros. Sci., 52 (2010), 2758.

12) S. Matsuyama: Okure Hakai, Nikkan Kogyo Shimbun, Tokyo, (1989), 70.

13) K. Takai, H. Shoda, H. Suzuki and M. Nagumo: Acta Mater., 56 (2008), 5158.

14) H. Shoda, M. Suzuki, K. Takai and Y. Hagihara: Tetsu-to-Hagané, 95 (2009), 573 (in Japanese).

15) M. A. V. Devanathan and Z. Stachurski: Proc. R. Soc. Lond. Ser. A, 270 (1962), 90.

16) M. A. V. Devanathan, Z. Stachurski and W. Beck: J. Electrochem. Soc., 110 (1963), 886.

17) M. A. V. Devanathan and Z. Stachurski: J. Electrochem. Soc., 111 (1964), 619.

18) W. Beck, J. O. M. Bockris, J. McBreen and L. Nanis: Proc. R. Soc. Lond. A, 290 (1966), 220.

19) K. Takai, S. Hirota, H. Suzuki, Y. Seko and H. Motohashi: J. Jpn. Inst. Met. Mater., 77 (2013), 615 (in Japanese).

20) A. Nishikata, T. Takahashi, H. Bao-Rong and T. Tsuru: Zairyo-toKankyo, 43 (1994), 188 (in Japanese).

21) T. Tsuru, Y. Huang, M. R. Ali and A. Nishikata: Corros. Sci., 47 (2005), 2431.

22) E. Tada and Y. Miura: ISIJ Int., 56 (2016), 444.

23) M. Stratmann and H. Streckel: Corros. Sci., 30 (1990), 681.

24) M. Stratmann and H. Streckel: Corros. Sci., 30 (1990), 697.

25) M. Stratmann, H. Streckel, K. T. Kim and S. Crockett: Corros. Sci., 30 (1990), 715.

26) T. Tsuru, Y. Yokoyama and J. Wang: Proc. 39th Japan Corrosion Conf., JSCE, Tokyo, (1992), 47.

27) A. Tahara and T. Kodama: Corros. Sci., 42 (2000), 655.

28) E. Tada and T. Tsuru: Bull. Iron Steel Inst. Jpn., 17 (2012), 43 (in Japanese).

29) E. Tada and A. Nishikata: ISIJ Int., 56 (2016), 424.

30) T. Omura, T. Kushida, T. Kudo, F. Nakasato and S. Watanabe: Zairyo-to-Kankyo, 54 (2005), 61 (in Japanese).

31) T. Kamimura, K. Kashima, K. Sugae, H. Miyuki and T. Kudo: Corros. Sci., 62 (2012), 34.

32) S. Ajito, E. Tada, A. Ooi and A. Nishikata: Mater. Trans., 60 (2019), 531. 